\title{
An Integrated Dual Ultrasonic Selective Powder Dispensing Platform for Three-Dimensional Printing of Multiple Material Metal/Glass Objects in Selective Laser Melting
}

DOI:

$10.1115 / 1.4041427$

Document Version

Accepted author manuscript

Link to publication record in Manchester Research Explorer

Citation for published version (APA):

Zhang, X., Wei, C., Chueh, Y-H., \& Li, L. (2018). An Integrated Dual Ultrasonic Selective Powder Dispensing Platform for Three-Dimensional Printing of Multiple Material Metal/Glass Objects in Selective Laser Melting. Journal of Manufacturing Science and Engineering, 141(1), 011003. [011003]. https://doi.org/10.1115/1.4041427

\section{Published in:}

Journal of Manufacturing Science and Engineering

\section{Citing this paper}

Please note that where the full-text provided on Manchester Research Explorer is the Author Accepted Manuscript or Proof version this may differ from the final Published version. If citing, it is advised that you check and use the publisher's definitive version.

\section{General rights}

Copyright and moral rights for the publications made accessible in the Research Explorer are retained by the authors and/or other copyright owners and it is a condition of accessing publications that users recognise and abide by the legal requirements associated with these rights.

\section{Takedown policy}

If you believe that this document breaches copyright please refer to the University of Manchester's Takedown Procedures [http://man.ac.uk/04Y6Bo] or contact uml.scholarlycommunications@manchester.ac.uk providing relevant details, so we can investigate your claim.

\section{OPEN ACCESS}




\title{
An Integrated Dual Ultrasonic Selective Powder Dispensing Platform for 3D Printing of Multiple Material Metal/Glass Objects in Selective Laser Melting
}

\author{
Xiaoji Zhang, first author ${ }^{1}$ \\ Laser Processing Research Centre, School of Mechanical, Aerospace and Civil \\ Engineering, The University of Manchester, Manchester M13 9PL, UK \\ xiaoji.zhang@postgrad.manchester.ac.uk \\ Chao Wei, second author \\ Laser Processing Research Centre, School of Mechanical, Aerospace and Civil \\ Engineering, The University of Manchester, Manchester M13 9PL, UK \\ chao.wei@postgrad.manchester.ac.uk
}

Yuan-Hui Chueh, third author Laser Processing Research Centre, School of Mechanical, Aerospace and Civil Engineering, The University of Manchester, Manchester M13 9PL, UK Yuan-hui.chueh@postgrad.manchester.ac.uk

Lin Li, fourth author ${ }^{1}$ Laser Processing Research Centre, School of Mechanical, Aerospace and Civil Engineering, The University of Manchester, Manchester M13 9PL, UK lin.li@manchester.ac.uk

\footnotetext{
${ }^{1}$ Corresponding authors, Mr. Xiaoji Zhang, Professor Lin Li.
} 


\section{ABSTRACT}

In this paper we present a new approach of combining point by point selective powder delivery with powder bed fusion for multiple material (metal/glass) components printing. Dual ultrasonic vibration was used to achieve stable flowrates of both $316 \mathrm{~L}$ steel and soda-lime glass powders which were dispensed selectively and separately. The effects of the stand-off distance and the scanning speeds on the quality of the formed layers were investigated. The results showed that the ratio between the stand-off distance and the powder size $(h / d)$ should be lower than 3 for accurate selective material deposition. However, in practical processing, for preventing the nozzle from being damaged by the parts, the stand-off distance was larger than 3 times of the powder size. Different laser processing parameters were developed for processing the metal and glass due to material property differences. The interfaces between $316 \mathrm{~L}$ and soda-lime glass were examined. A number of 3D objects consisting of metal and glass were printed using this method.

Keywords: multi-material; 316L; 3D printing, SLM, additive manufacturing, glass; powder feeding, ultrasonic;

\section{INTRODUCTION}

Complex full dense parts of different materials can be manufactured by Additive Manufacturing (AM), layer by layer. One of the advantages of additive manufacturing or $3 \mathrm{D}$ printing is to greatly reduce the number of components and assembly processes in complex engineering products. In practice, due to the requirement of different functionalities and material properties at different locations of a product, multiple materials are required. Metal components, as one of the most widely used materials in 
industrial applications, can be manufactured by powder bed fusion (PBF) and directed energy deposition (DED) [1]. DED, or known as laser cladding or laser engineered net shaping (LENS) have several advantages for multiple material AM. Firstly, these AM methods are mainly based on gas assisted point by point powder delivery suitable for multiple material deposition. Secondly, various types of materials can be applied, including both metallic powders and ceramic powders [1]. Vibrational powder delivery [2] and ultrasonic vibration on the substrate were also used to reduce the porosity [3, 4]. However, low dimensional accuracy, limitation in the complexity of component geometry and requirement of post process machining for finishing the part have been recognised as the main disadvantages of this AM method. In addition, the LENS system is mainly suitable for depositing metallic materials. Compared with LENS, selective laser melting (SLM), one of the PBFs, is capable of fully melting the powder material, producing fully dense near net-shape components of complex geometry without the need for post-processing for a variety of materials including metals, ceramics and polymer, and the component geometry resolution can reach 20-50 $\mu \mathrm{m}$ [5]. SLM of various metallic materials, including stainless steel, nickel alloy, titanium alloy, etc. have been widely investigated and this technology has been matured in terms of process parameters and material performance [6]. SLM has also been applied to printing ceramic materials, such as silica, soda-lime glass, and alumina [7-11]. However, so far SLM is limited to printing a single material in each layer due to the use of powder bed spreading material addition method. Therefore there is a need to understand the 
challenges and feasibility of 3D printing multiple materials of SLM, particularly over the same layer [12].

Multi-material SLM has many challenges including multi-material delivery, material contamination avoidance, material recycling, new software configuration considering multiple materials, varying process parameters for different materials, effects of one material on the other, and interfaces between different materials. In multi-material SLM, materials cannot be dispensed as in normal SLM powder bed spreading, because powders need to be deposited selectively on specific locations in each layer. According to Geldart's study [13], powders in the range between $10-50 \mu \mathrm{m}$ in size that are widely used in SLM are cohesive. Deposition of this kind of powders has been investigated using pneumatic, volumetric, screw/auger, electrostatic, and vibratory methods [14]. One of the most promising methods to control the powder flow is the use of a vibration actuator. Some researchers used ultrasonic vibration to deposit powders through a needle for other applications, not related to powder bed based SLM [15-20], which has been shown to be an effective way to dispense cohesive powders. AlJamal et al applied this feeding method with a single ultrasonic vibration actuator in selective laser melting of cooper and $\mathrm{H} 13$ tool steel, without combining with a powder bed system [12]. The latest relevant research conducted by Chao Wei et al at The University of Manchester investigated the bonding characteristics between $316 \mathrm{~L}$ and In718, and 316L and Cu10Sn using combined single actuator ultrasonic powder feeding and powder bed spreading [21]. Wang et al also [2] examined the flowrate stability of a 
single ultrasonic vibration powder feeding system with $316 \mathrm{~L}$ stainless steel powders having a particle size range of $45-150 \mu \mathrm{m}$ in laser cladding and direct metal deposition. However, powders in this range are sand-like and are typically used in direct laser deposition (DLD), not suitable for SLM. Factors affecting accurate and stable powder delivery of cohesive powders have not yet been reported. For SLM applications, the deposition quality in the layer is very important and it can directly influence the processing results of the part.

This research aimed at developing a stable fine powder selective point by point delivery system based on a novel dual ultrasonic vibration system and the material deposition quality was examined in detail for delivering fine 316L stainless steel and sola-lime glass powders. The system was integrated to an in-house SLM system and printing of multiple material 316L-glass components was investigated for the first time. The deposition mechanism and factors affecting the ultrasonic vibration feeding system were investigated. The characteristics of interfaces between both materials were examined.

\section{MATERIALS AND METHODS}

\subsection{The SLM procedure and materials}

Spherical 316L stainless steel powders (LPW-316-AAHH, 10-45 $\mu \mathrm{m}$, LPW Technology Ltd., UK) were selected as the candidate for metal printing in this research shown in Fig. 1 (a). Spherical soda-lime powders of two different size ranges $\left(30 \pm_{2} \mu \mathrm{m}\right.$ 
and $90 \pm 2 \mu \mathrm{m}$, supplied by Goodfellow) were mixed in a mass weight ratio of 1:3 (smaller powder : larger powder) according to the optimal packing equation of bimodal mixtures of spheres [22]. It is known that bimodal mixtures of spheres can improve packing density and also increase laser absorption and thermal conductivity according to the work of Tan, et al [22]. Ground finished 304 steel sheets of $25 \mathrm{~mm} \times 25 \mathrm{~mm} \times 12$ $\mathrm{mm}$ in dimension were used as the supporting substrates where the laser deposited components were built on.

An $x-y-z$ galvo scanner (Nutfield, 3XB 3-axis) was used to scan the laser beam with an $80 \mu \mathrm{m}$ focused beam spot size generated from a $500 \mathrm{~W}$ ytterbium single-mode, continuous wave (CW) fibre laser (IPG Photonics, YLR-500-WC) of a $1070 \mathrm{~nm}$ wavelength over the target powder bed. Nitrogen gas was used for gas shield in the sealed chamber during processing. Optimised laser processing parameters on both materials are shown in Table 1 [21].

\subsection{The dual ultrasonic vibrational powder feeding system}

In order to deliver multiple materials on the same layer selectively, two dual ultrasonic vibration feeding systems were mounted on an X-Y stage in the in-house SLM system for dispensing the $316 \mathrm{~L}$ and soda-lime glass powders, respectively (shown in Fig. 2 (a)). Different laser parameters were investigated for both materials to melt and solidify the layer selectively. After that, the building platform was lowered by the value of one layer thickness and the above process was repeated until the 3D part was completed. 
The structure of the dual ultrasonic powder delivery system is shown in Fig. 2 (b). Two standard piezoelectric transducers (PZT) at a $28 \mathrm{kHz}$ vibration frequency, a maximum 60 W vibration power, were used. As shown in Fig. 3 (a), the lower ultrasonic transducer provided vertical vibration to the delivery nozzle (made of a stainless steel surgical needle) with a very small orifice diameter $(0.2 \mathrm{~mm}-0.35 \mathrm{~mm}$ in this particular experiment). An aluminium bracket was tightly fixed to the lower PZT by an M10 screw through an anti-slip washer and a rubber washer for insulating heat from the PZT to the bracket. A stainless steel surgical needle was directly fixed at the bracket (Fig. 3 (b)), so that full vibrational power can be transferred to the needle. The upper PZT horizontally vibrated a fixed $50 \mathrm{ml}$ cylindrical powder hopper which had a $120^{\circ}$ and a $2 \mathrm{~mm}$ orifice, by which powders were dispensed to the feeding nozzle consistently. Powders could be compacted and jammed in the hopper by the counter force against the gravity of the powder from the $120^{\circ}$ orifice of the hopper after a long period (e.g. $>10$ minutes) of powder feeding. The horizontal projection of the counter forces could compact the powders in the middle of the orifice (e.g. the purple coloured powder shown in Fig. 4 (a)). In this case, the added vertical vibration at the bottom of the powder hopper not only breaks the force balance, but also increases compactness of the powders, causing jamming. The horizontal vibration from the upper PZT can reduce the support forces from the sidewalls and avoid powder jamming at the orifice of the hopper. The vertical vibration from the lower PZT can provide a vertical acceleration to powders in the feeding nozzle, with which the attractive force between cohesive powders could be 
broken (Fig. 4 (b)). A soft tube connected the hopper and the needle, so that the needle did not need to take the weight of the hopper, which can avoid the influence of the weight of powders on the powder feeding. Also the weight of powders can change the natural frequency of the system, so that resonance is disturbed. Two identical systems were mounted on an $x-y$ linear stage inside the in-house SLM system and the motion control was programmed using G-codes. An electric balance (from Ek-300i, A\&D Ltd) was used to record the powder flow weight automatically to a computer. The maximum load of the balance was $300 \mathrm{~g}$ and its resolution was $0.01 \mathrm{~g}$.

\subsection{Experimental set up of ultrasonic vibration feeding system}

Powder flowrate, i.e. the powder mass output through a nozzle within unit time, is an important parameter that would affect the material deposition. Stability of longtime powder dispensing using the ultrasonic powder dispensing systems can be very important in multi-material SLM additive manufacturing since the operations could be for a few hours continuously.

Theoretically, material flowability, dispensing force and counterforce are the three main factors that influence material delivery. The vibrational acceleration generates the dispensing force, and the counterforce (friction) is determined by the needle/nozzle geometry and properties of the powders. The powders used were standard spherical powder materials for SLM and thus the powder size distribution and spherical shape were ideal for SLM. The powders were dried at $120{ }^{\circ} \mathrm{C}$ for 12 hours in a 
vacuum oven before the experiments. The amplitude and frequency are two main factors for the PZTs according to Matsusaka's vibrational acceleration equation [15]

$$
\alpha=\mathrm{A}(2 \pi f)^{2}
$$

where $\alpha$ is the vibrational acceleration, $A$ is the amplitude and $f$ is the frequency. A

constant $28 \mathrm{kHz}$ frequency at a maximum power of $60 \mathrm{~W}$ (corresponding to about $5 \mu \mathrm{m}$ amplitude) was used in the experiments. At a constant frequency, lower power generates lower vibration amplitudes. Therefore, in order to know the influences of the vibrational power, $6 \mathrm{~W}, 24 \mathrm{~W}, 42 \mathrm{~W}$ and $60 \mathrm{~W}$ were used for dispensing of both materials.

In terms of the powder feeding nozzle geometry, according to Qi's study [23], the angle of the orifice between $30^{\circ}$ and $60^{\circ}$ could generate good flows and the feeding can be accurately controlled with a ratio of 3-8 between the orifice diameter and the maximum powder size. Therefore, the orifice angle was $30^{\circ}$ in the experiments. The orifice diameters used in $316 \mathrm{~L}$ powder dispensing were $0.2 \mathrm{~mm}$ and $0.3 \mathrm{~mm}$. For sodalime glass powders, feeding nozzle diameters of $0.3 \mathrm{~mm}$ (three times of the maximum powder size) and $0.35 \mathrm{~mm}$ were compared.

In SLM, two factors of powder delivery are important: flowrate stability and the flowrate. Long-time stable flowrate is necessary. Therefore, the powder flowrate was measured for 10 minutes. Table 2 shows the specific parameter ranges for the flowrate tests. 


\subsection{Experimental set up of inclined single-track deposition}

The purpose of this experiment is to rapidly examine the effect of nozzle stand distance to the target surface on deposition track characteristics. The relationship between the deposition track geometry and the powder flow rate is shown in Equation (2).

Powder density $\times$ cross-section area $\times$ scanning speed $=$ flowrate

Assuming the flowrate and the powder density are constant during deposition. The powder delivery scanning speed, stand-off distance (the distance of the tip of the nozzle to the top of the substrate [20]) and the feeding nozzle orifice diameter control the cross-section area of the deposited track. Therefore, the stand-off distance and the scanning speed are two main factors affecting the deposition accuracy and quality. It is clear that higher powder delivery scanning speeds would lead to smaller cross-section areas. Therefore, in order to understand the effect of the nozzle/substrate stand-off distance on deposited line cross-section height and width, the powder delivery scanning speed was kept constant and the stand-off distance was increased linearly. Powder lines were deposited onto an inclined plate with a linear increasing height as shown in Fig. 5. The figure demonstrates the schematic of the inclined single-track experiments where $\mathrm{H}$ is the highest point of the substrate ( $1 \mathrm{~mm}$ from the base), $\mathrm{h}$ is the stand-off distance which was $0.02 \mathrm{~mm}$ at the initial point. The horizontal length of the substrate was 64 $\mathrm{mm}$ in this experiment. Therefore, the stand-off distance of a position can be calculated 
by the horizontal displacement and the slope $(\tan \theta=1 / 64)$. The inclined glass plate had a

flat and smooth surface and it was covered by a plastic film for powder catchment and observation. A Keyence VHX-5000 optical microscope was used for measuring line widths and line cross sections. All parameters for powder dispensing were the same as those in Table 2. Therefore, the powder flowrate was constant. The powder delivery scanning speed was $3000 \mathrm{~mm} / \mathrm{min}$. 316 powders were used in this experiment. The vibrational power was $6 \mathrm{~W}$ and the needle/nozzle orifice was $0.3 \mathrm{~mm}$, which was explained in Section 3.2. The corresponding flowrates are shown in Table 3.

\section{RESULTS AND DISCUSSION}

\subsection{Powder flowrate characteristics}

In order to demonstrate the advantages of the dual PZT (piezoelectric transducer) feeding system, the flowrate of a single PZT feeding system was compared. Feeding of soda-lime powders with $42 \mathrm{~W}$ PZT power and $0.35 \mathrm{~mm}$ nozzle/needle diameter was examined. It can be seen from Fig. 6 that the flowrate was stable initially, but it became lower after about $450 \mathrm{~s}$. This could be caused by partial powder jamming and powder compacting.

Flowrates of $316 \mathrm{~L}$ and soda-lime glass powders with different needle/nozzle diameters and powers for the dual PZT feeding system are shown in Table 3. For a feeding nozzle of a $0.2 \mathrm{~mm}$ diameter feeding $316 \mathrm{~L}$ powders, flowrates increased 
gradually with the increasing ultrasonic power. However, for the $0.3 \mathrm{~mm}$ diameter needle/nozzle, it sharply increased from about $3.38 \mathrm{mg} / \mathrm{s}$ at $6 \mathrm{~W}$ to about $12 \mathrm{mg} / \mathrm{s}$ when the vibration power was $24 \mathrm{~W}$ and the flowrate reached about $31.53 \mathrm{mg} / \mathrm{s}$ at the peak power of $60 \mathrm{~W}$. Compared with 316L, soda-lime glass powders showed smaller differences at different powers. For the $0.35 \mathrm{~mm}$ diameter nozzle, the flowrates increased gradually with the power from about $3.38 \mathrm{mg} / \mathrm{s}$ at $6 \mathrm{~W}$ to about $5.80 \mathrm{mg} / \mathrm{s}$ at $60 \mathrm{~W}$.

From Fig. 7(a) and (b), 316L powder line at different PZT powers increased slightly without fluctuations and its gradient was constant. However, when the power reached $24 \mathrm{~W}$ the flowrate started to increase sharply, which meant the powder flow would increase very quickly at higher power when the ratio between the orifice $(0.3$ $\mathrm{mm})$ and the powder size $(10-45 \mu \mathrm{m})$ was about 7 , a relatively large value. The bimodal soda-lime glass powders in this experiment were a mixture of 1:3 (30 $\mu \mathrm{m}: 90 \mu \mathrm{m})$ powders. Powders of $90 \mu \mathrm{m}$ diameter were sand-like, thus the flowability was very good. However, the $30 \mu \mathrm{m}$ diameter powders were very cohesive and were unable to be delivered directly using the ultrasonic delivery system. For the bimodal mixture when the $0.3 \mathrm{~mm}$ and $0.35 \mathrm{~mm}$ diameter nozzles were used, the glass powders flowed very well and the flowrate was constant as shown in Fig. 7 (c) and (d). Similar to the 316L powders, the soda-lime glass powders also showed very good flowrates for the $0.3 \mathrm{~mm}$ 
diameter and $0.35 \mathrm{~mm}$ diameter needle/nozzle orifices for ultrasonic powers from $6 \mathrm{~W}$ to $60 \mathrm{~W}$.

\subsection{Deposition on an inclined substrate for stand-off distance effect} investigation

By comparing the flows of soda-lime glass powders at $60 \mathrm{~W}$, and $0.3 \mathrm{~mm}$ (Fig. 8 (a)) and $6 \mathrm{~W}, 0.35 \mathrm{~mm}$ (Fig. 8 (b)), it was found that the powder flow (a) spread around widely, while the flow (b) had a narrow stream. This is because at a higher power and smaller orifice diameter, inter impacts between powders were more severe than those at a lower power and larger orifice diameter. Therefore, lower ultrasonic vibrating power and a larger needle/nozzle orifice diameter were used in the experiments to enable more tightly controlled powder spread.

Fig. 9 shows the results of the line heights (i.e. deposition layer thickness) of $316 \mathrm{~L}$ on the inclined substrate. It increased sharply from 0 to about $150 \mu \mathrm{m}$ and then reduced gradually with the stand-off distance increasing. When the stand-off distance reached $1000 \mu \mathrm{m}$, namely the highest point in this experiment, the line height reduced to about $100 \mu \mathrm{m}$, which was about twice of the maximum powder size.

As shown in Fig. 5, the deposited line can be divided into three regions. Region A: the ratio between the stand-off distance (h) and the powder size (d) was less than 1. Region $\mathrm{B}$ : this ratio was $1-3$. Region $\mathrm{C}$ : this ratio was greater than 3 . In the initial part of 
the line, namely Region A (Fig. 10 (a)), the line height (thickness of the deposited layer) was less than $27 \mu \mathrm{m}$ that was equal to its corresponding stand-off distance. The line top was in contact with the powder delivery nozzle. Therefore, it was scraped by the nozzle.

There was a transition from Region A to Region B. During the transition, the line height increased with the increase of the stand-off distance until the stand-off distance reached about $150 \mu \mathrm{m}$. The line width was similar to that of Region $A$, while the line height was much higher (about $150 \mu \mathrm{m}$ according to Fig. 10 (d)). The top surface of the powder line was swept by the orifice edge to form the trapezoid cross section and the clear edge of the line can be seen. In Region $B$, the $h / d$ ratio was between 1 and 3 . In Region C (Fig. 10 (c)), since the powder delivery nozzle was not in contact with the top surface of the delivered powder lines, when the ratio $\mathrm{h} / \mathrm{d}$ was more than 3 , the line was formed by the powder in free fall by gravity. The cross-section shape was like a mountain and was decided by the powder cohesion. With the stand-off distance increasing further, the line width increased and the line height reduced. Powders may have spread out of the line due to high stand-off distance of the powder delivery nozzle.

For experiments on soda-lime glass powders, the needle/nozzle orifice diameter was $0.35 \mathrm{~mm}$ and the vibrational power was $6 \mathrm{~W}$. Fig. 11 shows the line height during the deposition. In Fig. 12 (a), the powders could not be dispensed onto the plate until the stand-off distance reached $100 \mu \mathrm{m}$. At the initial stage of the powder line deposition, the powders were scattered. A line could be formed when the stand-off distance reached about $163 \mu \mathrm{m}$ and the line height was about $128 \mu \mathrm{m}$ as shown in Fig. 
12 (b). The line height increased with the increase of the stand-off distance until the stand-off distance reached about $300 \mu \mathrm{m}$ that is three times of the biggest powder size (Fig. 12 (c)). After this, the line height reduced gradually, while the line width increased. The lowest line height (Fig. 12 (d)) was about $180 \mu \mathrm{m}$ that is also the thinnest layer thickness, which is about twice the largest powder size. It can be seen from Fig. 15 (e) that the cross section of each region was relatively trapezoid instead of triangular.

According to the results shown in Fig. 9 and 11, a simple first-order formula can be developed to help understand the approximate line heights of different stand-off distance. The formula is shown below as:

$$
\begin{gathered}
y=x \quad(x / d \leq 3) \\
y=3 d-\frac{1}{17}(x-3 d) \quad(3<x / d \leq 20)
\end{gathered}
$$

where $y$ is the line height $(\mu \mathrm{m}), d$ is the powder size $(\mu \mathrm{m})$, and $x$ is the stand-off distance $(\mu \mathrm{m})$. From Equation (3), it is quick to estimate the layer thickness with the certain stand-off distance in practical processing for the specific materials used. Therefore, the layer thickness can be adjusted by changing the stand-off distance to apply different processing parameters in SLM.

From the results of deposition on the inclined substrate of $316 \mathrm{~L}$ and soda-lime glass powders, it can be seen that the line cross-section shape was formed by different forces in different regions, as shown in Fig. 13. The line height (i.e. deposited layer 
thickness) increased first in Region $A$ and $B$ and it peaked at the three times the maximum powder size. When the stand-off distance exceeded three times of the powder size, the powder nozzle was not in contact with the delivered line top surface and the line height started to reduce slightly. Finally, the line height reduced to twice the maximum powder size. In practice, for preventing the nozzle from being damaged by the parts, the stand-off distance was larger than 3 times of the powder size..

\subsection{Effects of powder delivery scanning speed on the deposited powder line}

\section{geometry}

As shown in Fig. 14, effects of the powder delivery scanning speed of both materials were also investigated. Parameters and results of line widths measured by the VHX-5000 microscope are listed in Table 4. Results in Table 4 directly show that the higher the powder delivery speed was, the narrower the line was, which also agreed with the findings of Chianrabutra et al [20]. For 316L powders, lines were continuous and uniform at different speeds. On the contrary, soda-lime powder lines were intermittent, especially at $3000 \mathrm{~mm} / \mathrm{min}$. This is because the hard and light glass powders spread more quickly with higher kinetic energy when impacting on the substrate at high scanning speeds. Compared with soda-lime glass powders, 316L powders have higher mass density, so that they could stay in the line even though the speed was high.

The optimized deposition parameters are shown in Table 5. The hatch space between lines was $0.5 \mathrm{~mm}$ and the scanning speed was $3000 \mathrm{~mm} / \mathrm{min} .50 \mathrm{~mm} \times 50 \mathrm{~mm}$ 
squares were deposited using $316 \mathrm{~L}$ and soda-lime glass powders, respectively (Fig. 15 (a) and (b)) to demonstrate large area uniform deposition using the system. A pattern of 'LPRC' was made by soda-lime glass and 316L powders as shown in Fig. 15 (c). The powders were stacked at the start the corners, which was caused by the acceleration/deceleration during turning directions. Alternative ways can be applied to solve the problem. The powder accumulation at corners can be reduced by using lower flowrates during deposition. On the other hand, optimizing the scanning strategy can also solve this issue, which is being investigated.

\subsection{Interface characteristics in selective laser melting of $316 \mathrm{~L}$ stainless steel and}

\section{soda-lime glass powders}

In SLM, a substrate is necessary to anchor the part to avoid thermal distortion.

However, it was found that pure glass after being melted could not attach to the flat stainless steel substrate even when the substrate surface was rough (through sand blasting). However, melted glass can penetrate the rough surface of the $316 \mathrm{~L}$ parts made by SLM.

The volume energy density deposited in the material in SLM can be calculated using:

$$
E=\frac{p}{v h t}
$$


where $P$ is the laser power, $v$ is the scanning velocity, $h$ is the hatch spacing between scanned tracks and $t$ is the layer thickness. According to Fateri's optimum parameters [10] for glass melting: $60 \mathrm{~W}$ power, $67 \mathrm{~mm} / \mathrm{s}$ scanning speed, $0.05 \mathrm{~mm}$ hatch space, and $0.15 \mathrm{~mm}$ layer thickness [10], the volume energy density of soda-lime glass powders was $120 \mathrm{~J} / \mathrm{mm}^{3}$. In our research, the laser power was $180 \mathrm{~W}$, scanning speed was $300 \mathrm{~mm} / \mathrm{s}$, hatch space was $0.05 \mathrm{~mm}$ with an average layer thickness of $0.15 \mathrm{~mm}$ in order to increase processing efficiency. The volume energy density was about $114 \mathrm{~J} / \mathrm{mm}^{3}$ which is similar to the value in Fateri's studies[10]. A twenty-layer $5 \mathrm{~mm} \times 5 \mathrm{~mm}$ rectangular block of sola-lime glass was produced on a $1 \mathrm{~mm}$-thick $316 \mathrm{~L}$ deposited metal based layer as shown in Fig. 16. Transparent and smooth surface with some micro-cracks can be seen in Fig. 16 (a) and (b). Its edge was the Heat Affected Zone (HAZ) where the powders were not fully melted and many pores can be seen in Fig. 16 (a). Fig. 16 (c) shows the cross section of the block. It can be seen that the glass powders were fully melted in the body of the part. There were no lines of layers from the view of the cross section.

In order to investigate characteristics of the interface between $316 \mathrm{~L}$ and sodalime glass, two $20 \mathrm{~mm}$-long slots were produced with $6 \mathrm{~mm}$ width and $3 \mathrm{~mm}$ width, respectively (Fig. 17), which were deposited by the ultrasonic vibration feeding system and melted by the laser layer by layer. Ten layers were made and the total thickness was about $0.84 \mathrm{~mm}$. The layer of soda-lime glass powders were deposited by the powder 
delivery system and melted by the laser. The laser parameters and deposition parameters are shown in Tables 1 and 6, respectively.

From Fig. 17, it can be seen that the part with a $3 \mathrm{~mm}$-width was more fully melted than the part with a $6 \mathrm{~mm}$-width. The transparent part can be seen in the body of the part having a $3 \mathrm{~mm}$-width and pores can be seen in the part with a $6 \mathrm{~mm}$-width. This is because the heat generated by the laser accumulated during two short scans due to very low thermal conductivity of the glass material. However, heat dissipation was more during the two long scans. Therefore, the part with a $3 \mathrm{~mm}$-width was better melted than the wider one. This also means laser processing parameters and paths for fusing glass powders should be optimized according to different feature sizes, especially the scanning width of the part.

A good contact interface can be achieved even though the glass powders and metal powders were melted separately, which can be seen from the cross section of 3 $\mathrm{mm}$-wide part in Fig. 18. This is because as the volume energy density of melting glass $\left(114 \mathrm{~J} / \mathrm{mm}^{3}\right)$ is much higher than that of melting $316 \mathrm{~L}$ powders $\left(60 \mathrm{~J} / \mathrm{mm}^{3}\right)$. The $316 \mathrm{~L}$ surface can be re-melted during processing glass powders. Therefore, the molten pool can be formed by both materials and they can be fused together leading to a good bond between the two materials.

A simple 3D pendant was fabricated by this method in order to demonstrate as shown in Fig. 19. The ellipse body of the pendant was made by $316 \mathrm{~L}$ and a $3.5 \mathrm{~mm} \times 10$ 
$\mathrm{mm} \times 1.5 \mathrm{~mm}$ cuboid at the centre of the pendant was made by soda-lime glass. From the surface of the rectangular glass in Fig. 19 (a), it can be seen that the glass was partially transparent and there were many pores in the glass body, which impacted upon the appearance. Porosity in the body and at the edge (HAZ) was an issue that requires future investigation. Optimizing processing parameters or multiple scanning may be effective to improve the quality of the glass part.

As shown in Fig. 19 (b), a 3D Cu10Sn-glass pendant was fabricated by the same method. Cu10Sn copper-alloy spherical powders of $10-45 \mu m$ diameter (Makin Metal Powders Ltd. UK) were used in this investigation. The laser parameters for the Cu10Sn melting can be found in Table 1 . Two phenomena were noticed by comparing the $316 \mathrm{~L}-$ glass and $\mathrm{Cu}$ alloy/glass pendants. Firstly, the geometry of the copper alloy part was larger than the $316 \mathrm{~L}$ part due to high thermal conductivity and relatively lower melting point of copper alloy. Secondly, the glass part was not green in the $\mathrm{Cu}$ alloy/glass pendant as that in the $316 \mathrm{~L}$-glass part, which means the green colour in the glass could be generated by the $\mathrm{Fe}^{3+}$ to $\mathrm{Fe}^{2+}$ of the $316 \mathrm{~L}$-glass part.

\section{CONCLUSION}

In order to achieve multi-material SLM, a dual ultrasonic vibration feeding system which dispenses both metal and glass powders was combined with a propriety SLM system. For both the $316 \mathrm{~L}$ and soda-lime glass powders, the feeding system demonstrated long-time stable powder flowrates at different needle/nozzle orifice 
diameters of $0.2 \mathrm{~mm}-0.35 \mathrm{~mm}$ and different vibrational powers of $6 \mathrm{~W}-60 \mathrm{~W}$. Lower power and larger needle/nozzle orifice diameter were used in the experiments in order to generate narrower powder stream.

An inclined substrate was used to understand the effect of stand-off distance on deposited powder track geometry at a constant scanning speed. The results of both $316 \mathrm{~L}$ and glass showed that when the ratio between the stand-off distance and the powder size $(\mathrm{h} / \mathrm{d})$ was smaller than 3 , the line heights were nearly the same as the stand-off distance. However, when the ratio was more than 3, the line heights (i.e. layer thickness) reduced to twice the maximum powder size and the line width increased. In practical deposition, the stand-off distance was $1 \mathrm{~mm}$ to avoid collisions between the needle/nozzle and the part. The higher the scanning speed was, the narrower the line was. The deposited line widths at $3000 \mathrm{~mm} / \mathrm{min}$ were about $0.55 \mathrm{~mm}$ and $0.47 \mathrm{~mm}$ for the $316 \mathrm{~L}$ powders and soda-lime powders, respectively.

After laser melting of the deposited glass powders, transparent and smooth glass blocks could be obtained, while there were still some cracks on the soda-lime glass. In the Heat Affected Zone, powders were sintered instead of fully melted and porosity can be seen. On the basis of melting results of $3 \mathrm{~mm}$-wide glass and the $6 \mathrm{~mm}$-wide glass, it was noticed that laser processing parameters on glass powders should be optimized according to different feature sizes, especially the scanning width of the part. Sound metal-glass interfaces were achieved from both vertical and horizontal directions because both metal and glass were fused together by the molten pool by high energy 
density. 316L-glass and Cu10Sn-glass pendants were fabricated to demonstrate the application of the method. Patent applications are pending on the reported technology (UK patent application number: GB1810721.9, GB1706645.7, GB1800743.5 and PCT/GB2018/051093)

\section{ACKNOWLEDGMENT}

The Authors were grateful for The University of Manchester Ph. D. scholarships awarded to Mr. Chao Wei and Mr. Yuan-Hui Chueh. The authors would like to thank MAKIN Ltd., UK for providing copper alloy powders free of charge.

\section{FUNDING}

The University of Manchester Ph. D. scholarships awarded to Mr. Chao Wei and Mr.

Yuan-Hui Chueh

\section{NOMENCLATURE}

$A M$

Additive Manufacturing

PBF

Powder Bed Fusion

$D E D$

Directed Energy Deposition 
$D L D$

Direct Laser Deposition

CW

\author{
Continuous Wave
}

PZT

Piezoelectric Transducer

HAZ

Heat Affected Zone

FGM

Functionally Gradient Material 


\section{REFERENCES}

[1] Ferraris, E., Vleugels, J., Guo, Y., Bourell, D., Kruth, J.P., Lauwers, B., Shaping of engineering ceramics by electro, chemical and physical processes. CIRP AnnalsManufacturing Technology, 2016. 65(2): p. 761-784.

[2] Wang, W. and L. Li, High-quality high-material-usage multiple-layer laser deposition of nickel alloys using sonic or ultrasonic vibration powder feeding. Proceedings of the Institution of Mechanical Engineers, Part B: Journal of Engineering Manufacture, 2011. 225(1): p. 130-139\%@ 0954-4054.

[3] Ning, F.D., Hu, Y.B., Liu, Z.C., Cong, W.L., Li, Y.Z., Wang, X.L., Ultrasonic VibrationAssisted Laser Engineered Net Shaping of Inconel 718 Parts: A Feasibility Study. 45th Sme North American Manufacturing Research Conference (Namrc 45), 2017. 10: p. 771-778.

[4] Ning, F.D., Hu, Y.B., Liu, Z.C., Wang, X.L., Li, Y.Z., Cong, W.L., Ultrasonic VibrationAssisted Laser Engineered Net Shaping of Inconel 718 Parts: Microstructural and Mechanica Characterization. Journal of Manufacturing Science and EngineeringTransactions of the Asme, 2018. 140(6).

[5] Yap, C.Y., Chua, C.K., Dong, Z.L., Liu, Z.H., Zhang, D.Q., Loh, L.E., Sing, S.L., Review of selective laser melting: Materials and applications. Applied Physics Reviews, 2015. 2(4): p. $041101 \%$ 1931-9401.

[6] Bourell, D., Kruth, J.P., Leu, M., Levy, G., Rosen, D., Beese, A.M., Clare, A., Materials for additive manufacturing. CIRP Annals, 2017. 66(2): p. 659-681.

[7] Khmyrov, R.S., Grigoriev, S.N., Okunkova, A.A., Gusarov, A.V., On the possibility of selective laser melting of quartz glass. Physics Procedia, 2014. 56: p. 345-356 \%@1875-3892.

[8] Khmyrov, R.S., Protasov, C.E., Grigoriev, S.N., Gusarov, A.V., Crack-free selective laser melting of silica glass: single beads and monolayers on the substrate of the same material. The International Journal of Advanced Manufacturing Technology, 2016.85(5-8): p. 1461-1469\%@ 0268-3768.

[9] Protasov, C.E., Khmyrov, R.S., Grigoriev, S.N., Gusarov, A.V., Selective laser melting of fused silica: Interdependent heat transfer and powder consolidation. International Journal of Heat and Mass Transfer, 2017. 104: p. 665-674 \%@ 0017-9310.

[10] Fateri, M. and A. Gebhardt, Selective Laser Melting of Soda - Lime Glass Powder. International Journal of Applied Ceramic Technology, 2015. 12(1): p. 53-61 \%@ 1744-7402.

[11] Yves-Christian, H., Jan, W., Wilhelm, M., Konrad, W., Reinhart, P., Net shaped high performance oxide ceramic parts by selective laser melting. Physics Procedia, 2010. 5: p. 587-594 \%@1875-3892. 
[12] Al-Jamal, O., S. Hinduja, and L. Li, Characteristics of the bond in Cu-H13 tool steel parts fabricated using SLM. CIRP Annals-Manufacturing Technology, 2008. 57(1): p. 239-242.

[13] Geldart, D., N. Harnby, and A.C. Wong, Fluidization of cohesive powders. Powder Technology, 1984.37(1): p. 25-37\%@ 0032-5910.

[14] Stichel, T., Laumer, T., Baumuller, T., Amend, P., Roth, S., Powder layer preparation using vibration-controlled capillary steel nozzles for Additive Manufacturing. 8th International Conference on Laser Assisted Net Shape Engineering (Lane 2014), 2014. 56: p. 157-166.

[15] Matsusaka, S., M. Urakawa, and H. Masuda, Micro-feeding of fine powders using a capillary tube with ultrasonic vibration. Advanced Powder Technology, 1995. 6(4): p. 283-293\%@1568-5527.

[16] Matsusaka, S., K. Yamamoto, and H. Masuda, Micro-feeding of a fine powder using a vibrating capillary tube. Advanced Powder Technology, 1996. 7(2): p. 141-151\%@1568-5527.

[17] Lu, X., S. Yang, and J.R.G. Evans, Dose uniformity of fine powders in ultrasonic microfeeding. Powder Technology, 2007. 175(2): p. 63-72 \%@ 0032-5910.

[18] Lu, X., S. Yang, and J.R.G. Evans, Studies on ultrasonic microfeeding of fine powders. Journal of Physics D: Applied Physics, 2006. 39(11): p. 2444 \%@ 00223727.

[19] Lu, X., S. Yang, and J.R.G. Evans, Microfeeding with different ultrasonic nozzle designs. Ultrasonics, 2009. 49(6): p. 514-521 \%@ 0041-624X.

[20] Chianrabutra, S., B.G. Mellor, and S. Yang, A Dry Powder Material Delivery Device for Multiple Material Additive Manufacturing. University of Southampton, UK, 2014.

[21] Wei, C., Li, L., Zhang, X.J., Chueh, Y.H., 3D printing of multiple metallic materials via modified selective laser melting. CIRP Annals-Manufacturing Technology, 2018. 67(1): p. 245-248.

[22] Tan, J.H., W.L.E. Wong, and K.W. Dalgarno, An overview of powder granulometry on feedstock and part performance in the selective laser melting process. Additive Manufacturing, 2017. 18: p. 228-255.

[23] Qi, L., Zeng, X., Zhou, J., Luo, J., Chao, Y., Stable micro-feeding of fine powders using a capillary with ultrasonic vibration. Powder Technology, 2011. 214(2): $p$. 237-242\%@0032-5910. 


\section{Fig. Captions List}

Fig. 1 Metal and glass powders used in this research imaged using the VHX-

5000 optical microscope. a) 316L stainless steel powders, b) Bimodal

soda-line glass powders.

Fig. 2 The schematic of the multi-material SLM system used in this research (1

Upper PZT; 2 Lower PZT; 3 Hopper; 4 Soft tube; 5 Joint; 6 Needle/nozzle;

7 Bracket; 8 M10 screw with anti-slip washer; 9 Insulation rubber

washer; $10 \mathrm{M} 3$ screw for fixing the needle)

Fig. 3 The structure of the dual ultrasonic vibration feeding

Fig. 4 Schematic of powders dropping from the hopper and the nozzle/needle

Fig. 5 Schematic of the inclined single track test

Fig. 6 Comparing the mass flow over time using a single PZT feeding system

Fig. 7 Flowrates of $316 \mathrm{~L}$ powders and soda-lime glass powders using the dual

PZT powder feeding system

Fig. 8 Comparison of flows of (a) smaller orifice diameter and a higher

ultrasonic vibrating power, and (b) a larger orifice diameter and a lower ultrasonic vibration power

Fig. 9 The line heights with linear increasing stand-off distance of 316L 
powders

Fig. 10 Line width and cross section of the deposited 316L powder line

Fig. 11 The line heights with linear increasing of stand-off distance of soda-lime glass powders

Fig. 12 Line width and cross section of the deposited soda-lime glass powders

Fig. 13 Schematic of line forming mechanism in each region

Fig. $14 \quad$ Deposited lines at different speeds

Fig. 15 Layers deposited by the system, (a) and (b) are the square layers; (c) is the pattern 'LPRC' from two different materials: 316L (outside) and soda lime glass (inside).

Fig. 16 The laser melted soda-lime glass block

Fig. 17 Comparison between the melted $3 \mathrm{~mm}$ glass and $6 \mathrm{~mm}$ glass

Fig. 18 The interface between metal and glass of the $3 \mathrm{~mm}$ width part from the cross section view

Fig. 19 The demonstration of metal-glass part made by the method 


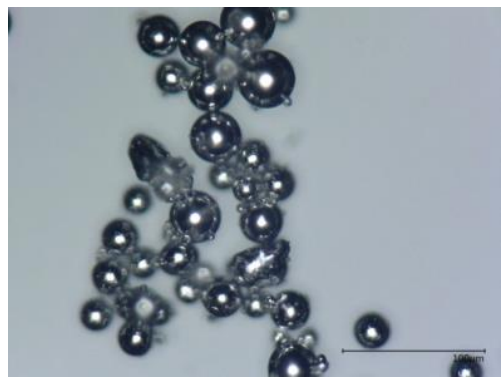

(a)

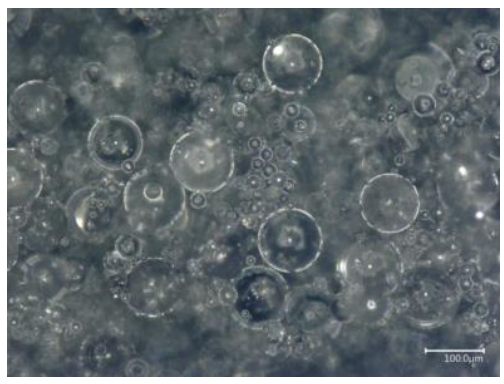

(b)

Fig. 1. Metal and glass powders used in this research imaged using the VHX-5000 optical microscope. a) 316L stainless steel powders, b) Bimodal soda-line glass powders.
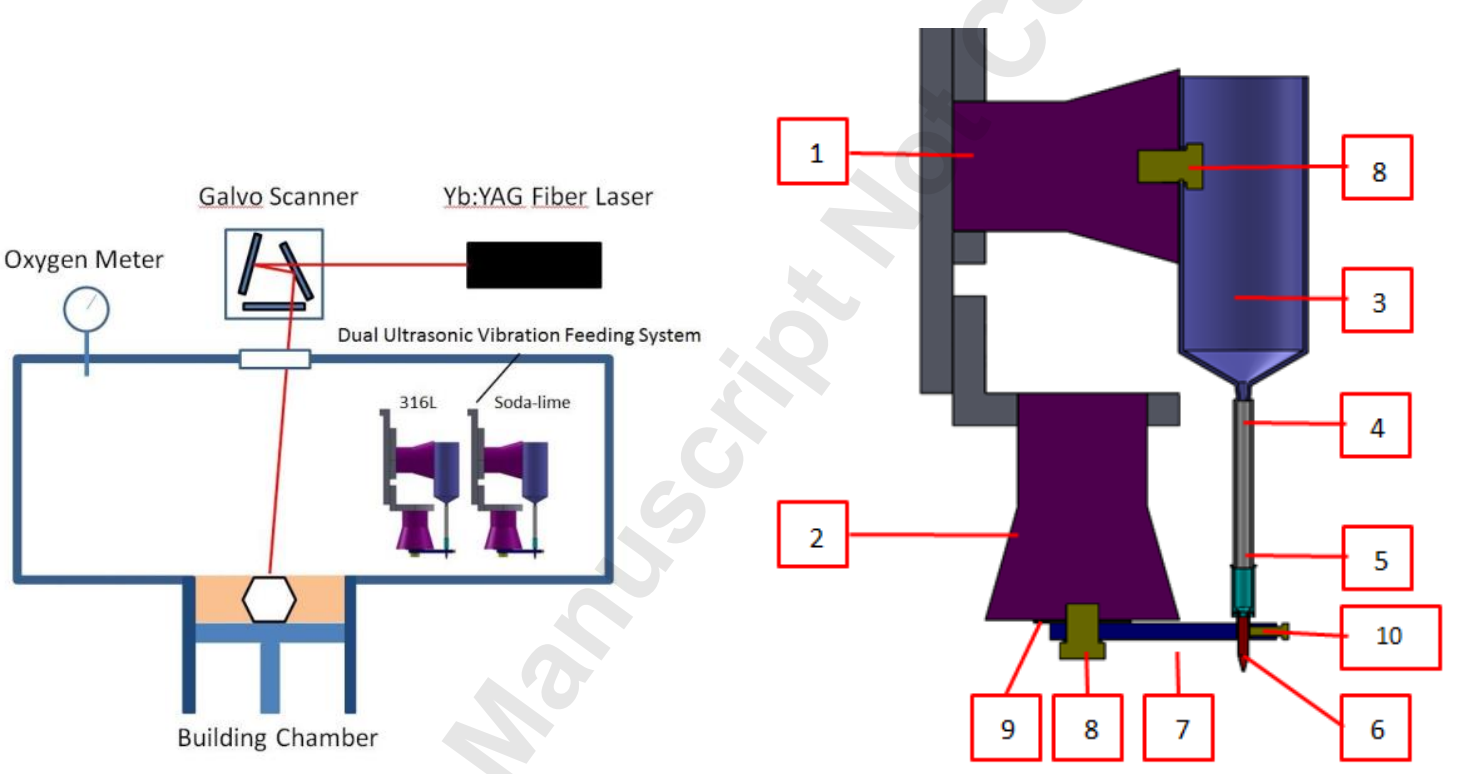

(a) The multi-material SLM system (b) The 2D schematic of the dual ultrasonic vibration feeding system

Fig. 2. The schematic of the multi-material SLM system used in this research (1 Upper PZT; 2 Lower PZT; 3 Hopper; 4 Soft tube; 5 Joint; 6 Needle/nozzle; 7 Bracket; 8 M10 screw with anti-slip washer; 9 Insulation rubber washer; 10 M3 screw for fixing the needle) 

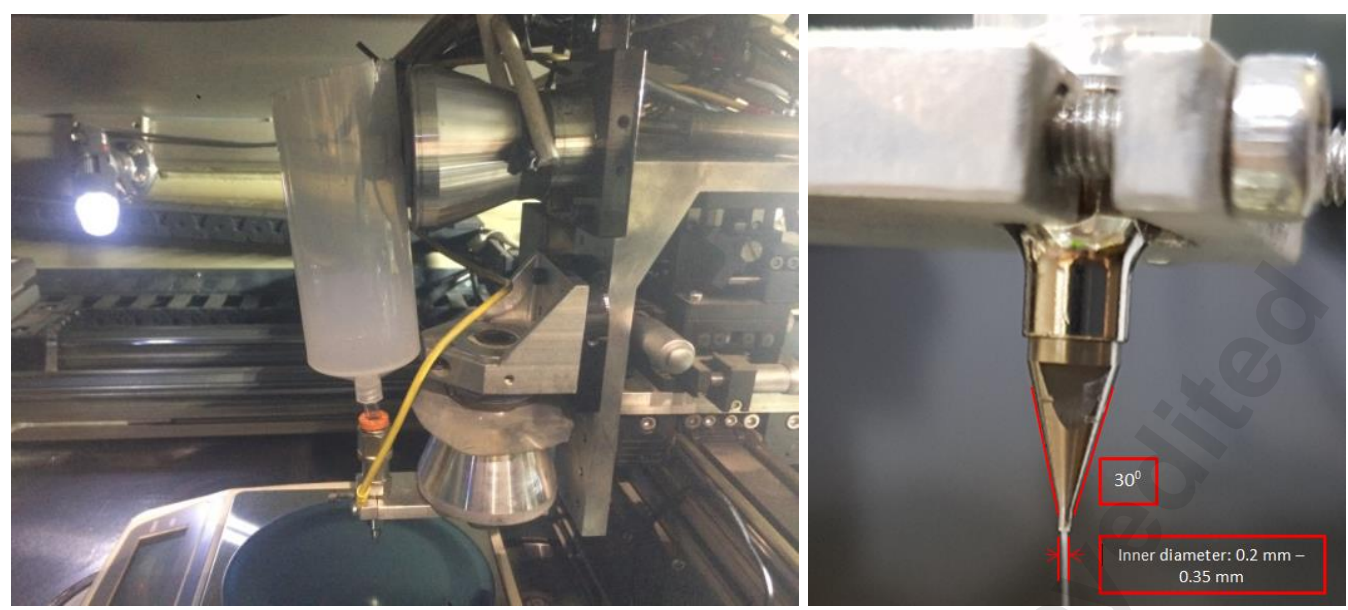

(a) The feeding system (b) The nozzle/needle of the powder feeding system

Fig. 3. The structure of the dual ultrasonic vibration feeding

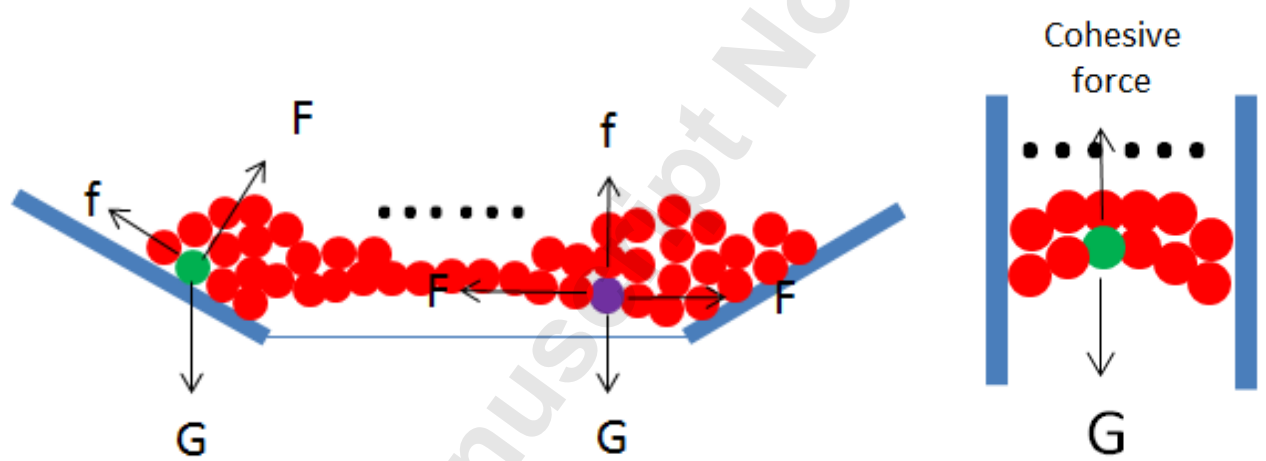

(a) $2 \mathrm{~mm}$ orifice diameter

(b) $0.3 \mathrm{~mm}$ orifice diameter

Fig. 4. Schematic of powders dropping from the hopper and the nozzle/needle 


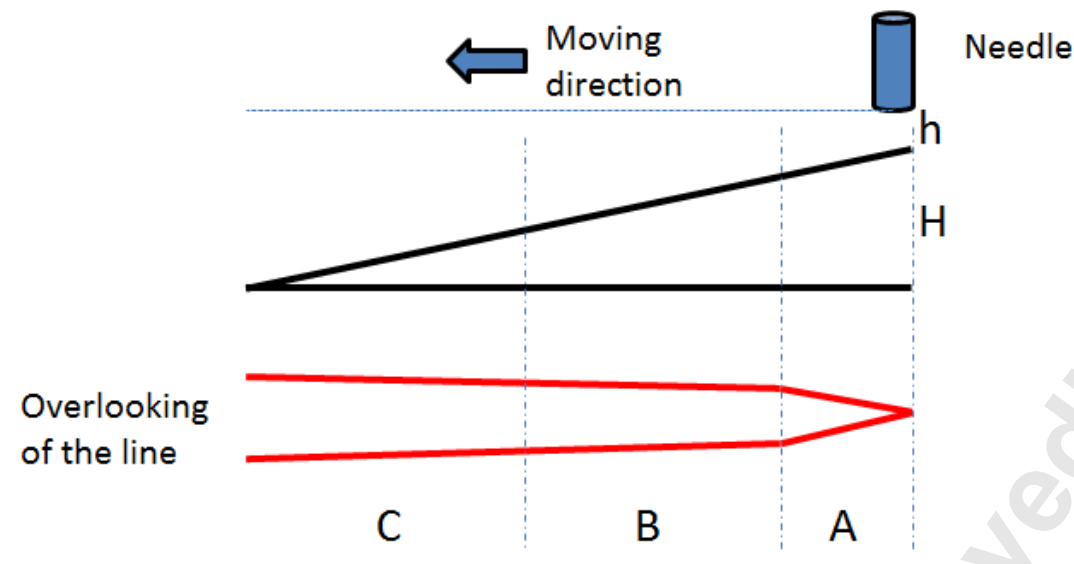

Fig. 5. Schematic of the inclined single track test

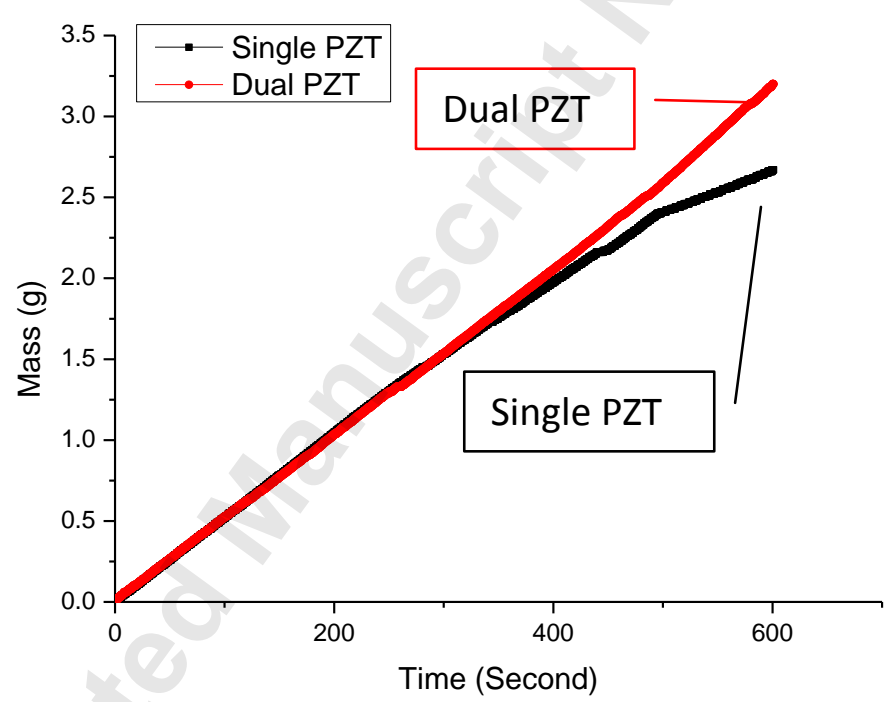

Fig. 6. Comparing the mass flow over time using a single PZT feeding system 


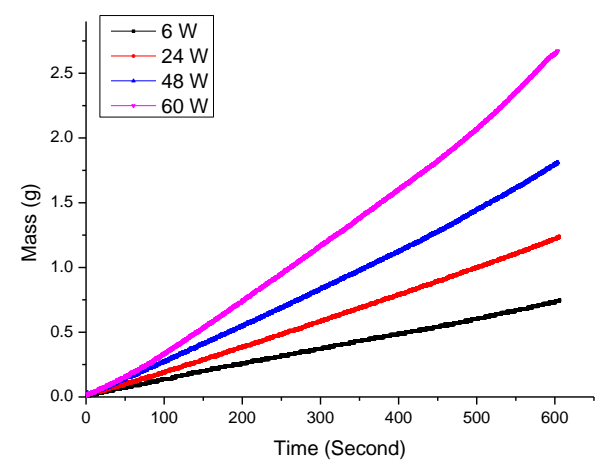

(a) $316 \mathrm{~L}$ powders, $0.2 \mathrm{~mm}$

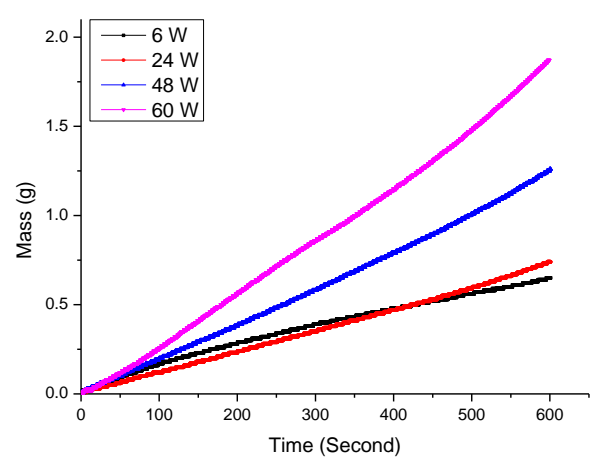

(c) soda-lime powders, $0.3 \mathrm{~mm}$

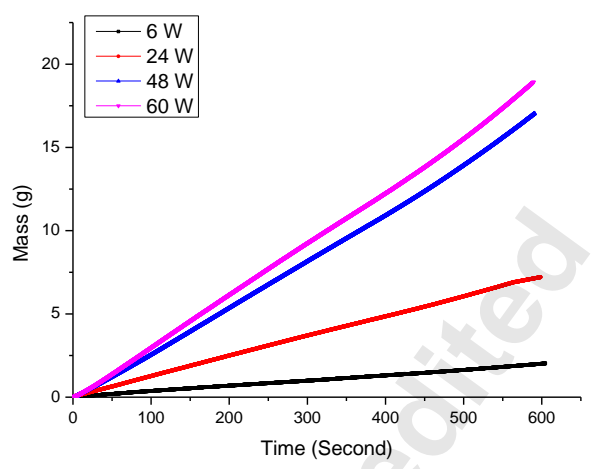

(b) $316 \mathrm{~L}$ powders, $0.3 \mathrm{~mm}$

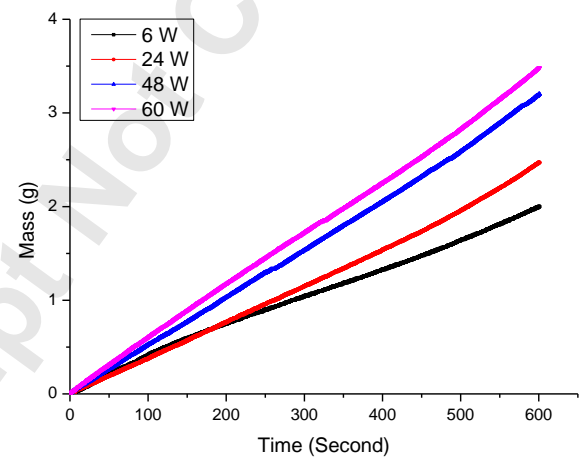

(d) soda-lime powders, $0.35 \mathrm{~mm}$

Fig. 7. Flowrates of $316 \mathrm{~L}$ powders and soda-lime glass powders using the dual PZT powder feeding system
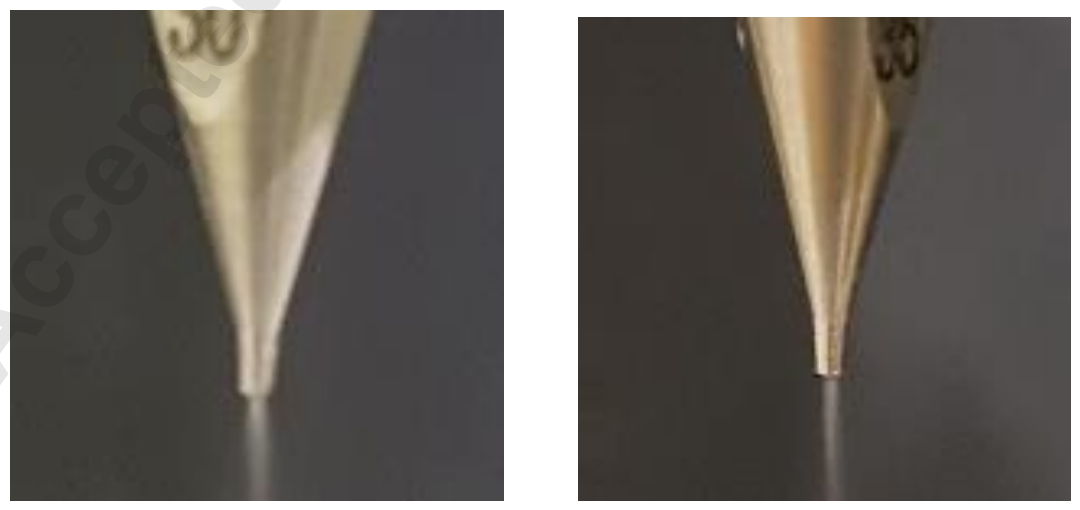
(a) (b)

Fig. 8. Comparison of flows of (a) smaller orifice diameter and a higher ultrasonic vibrating power, and (b) a larger orifice diameter and a lower ultrasonic vibration power

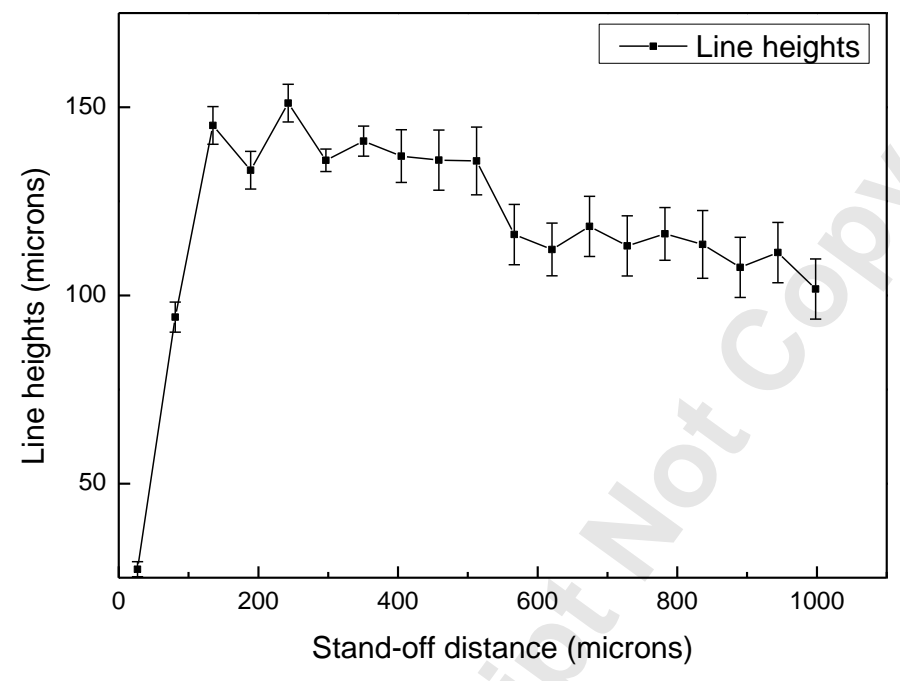

Fig. 9. The line heights with linear increasing stand-off distance of 316L powders

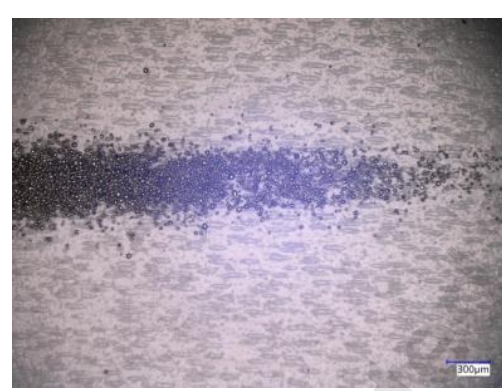

(a) Region A

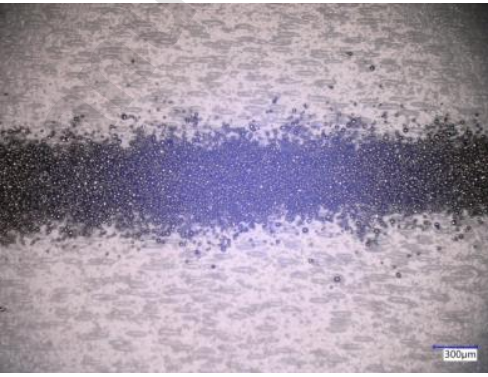

(b) Region B

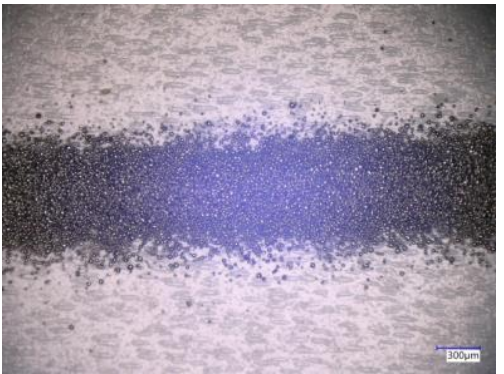

(c) Region C 


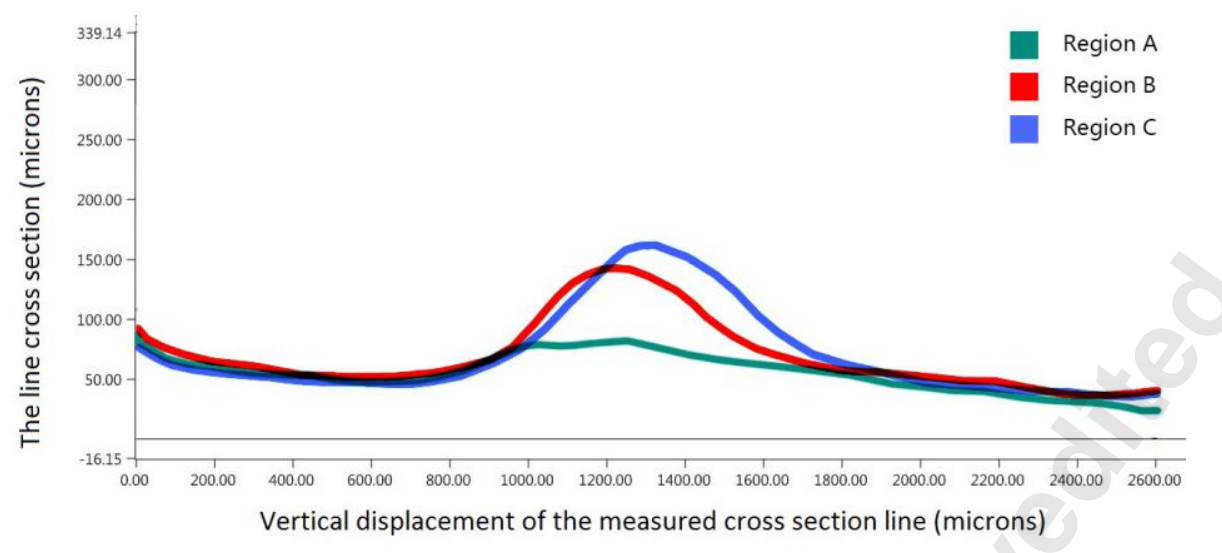

(d) The cross section of the deposited line in (a), (b), and (c)

Fig. 10. Line width and cross section of the deposited 316L powder line

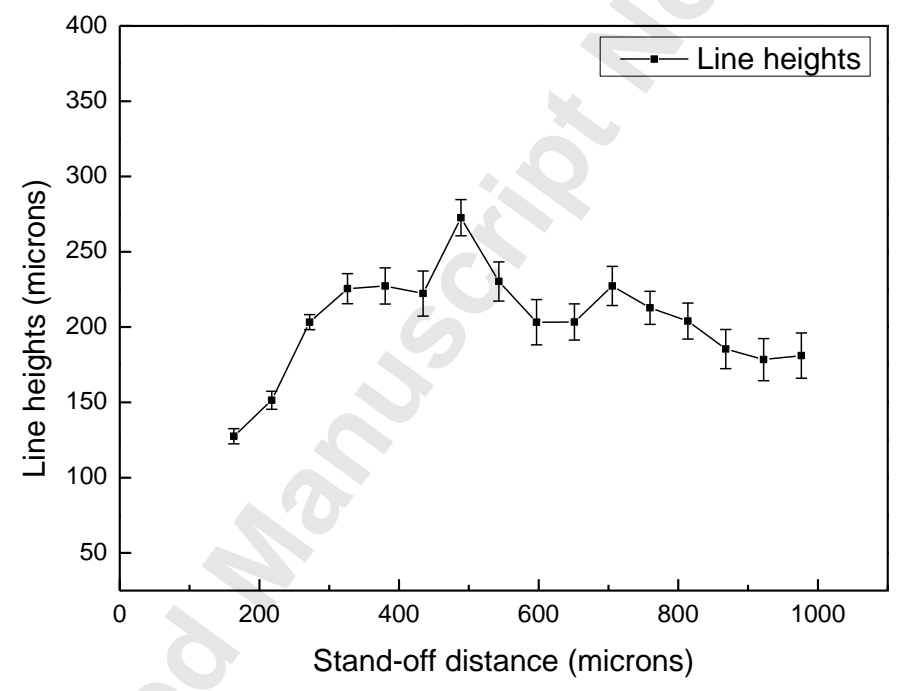

Fig. 11. The line heights with linear increasing of stand-off distance of soda-lime glass

powders 


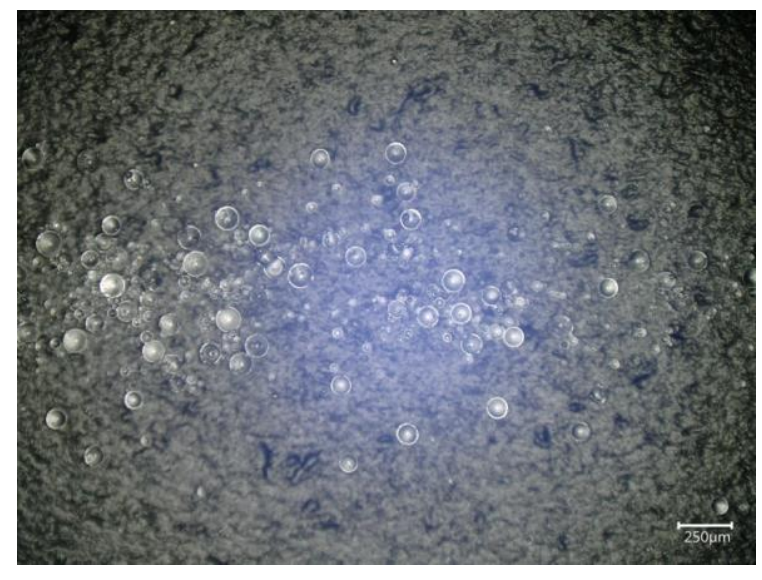

(a) The initial part of the line

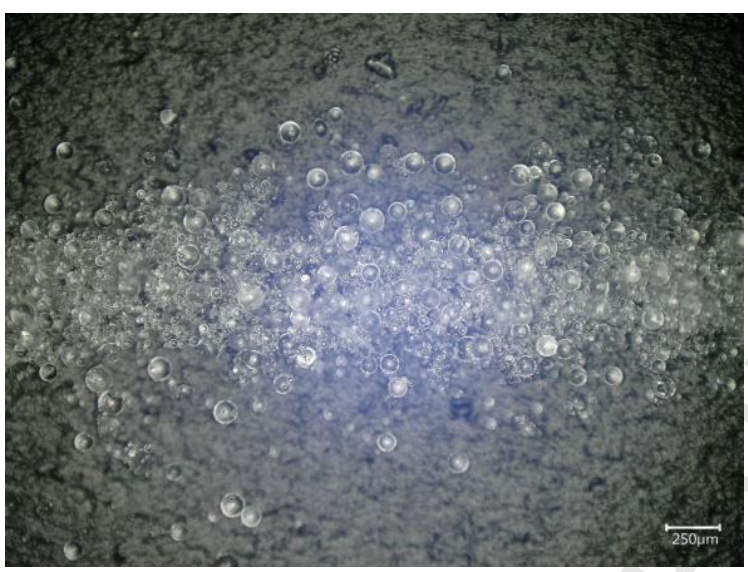

(c) Region B

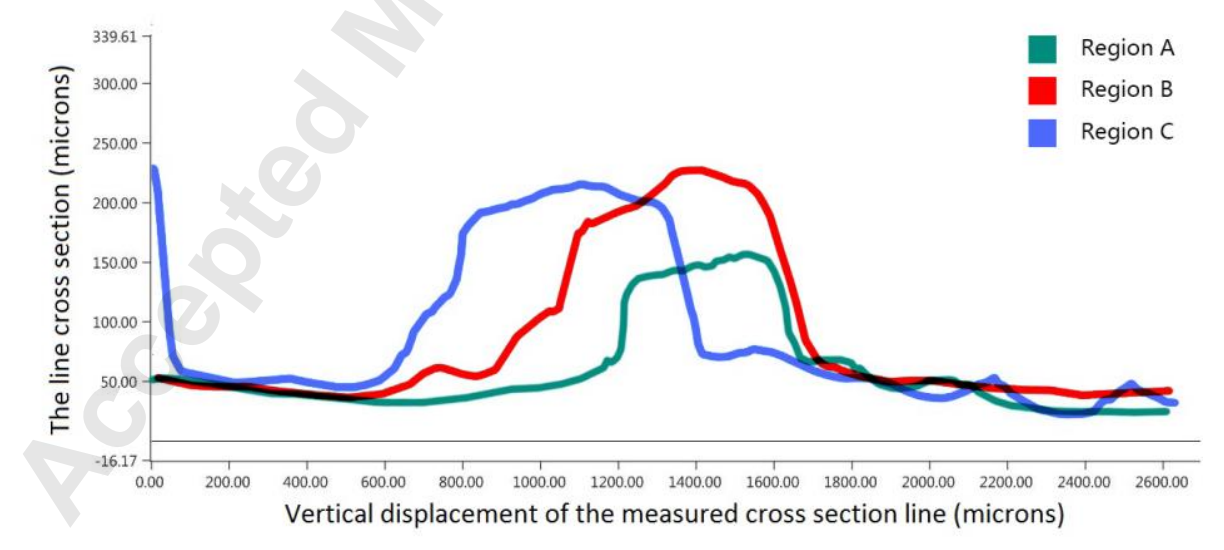

(e) The cross section of the line in (b), (c), and (d)

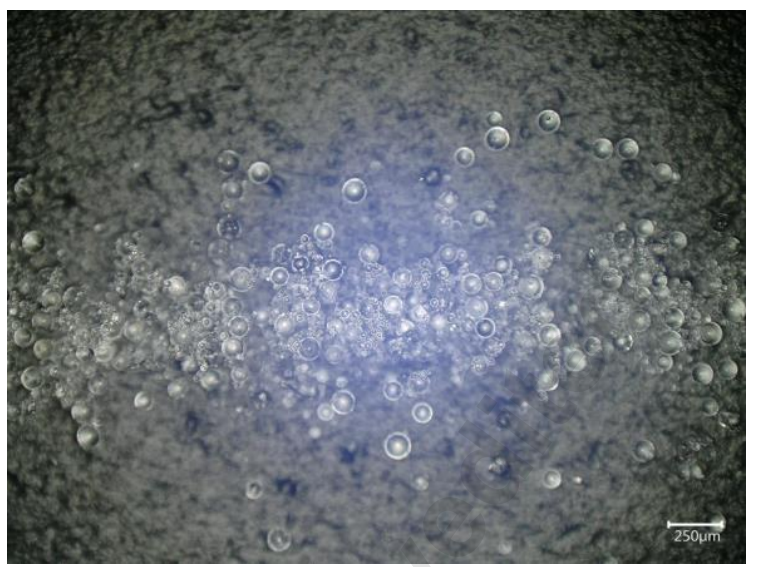

(b) Region A

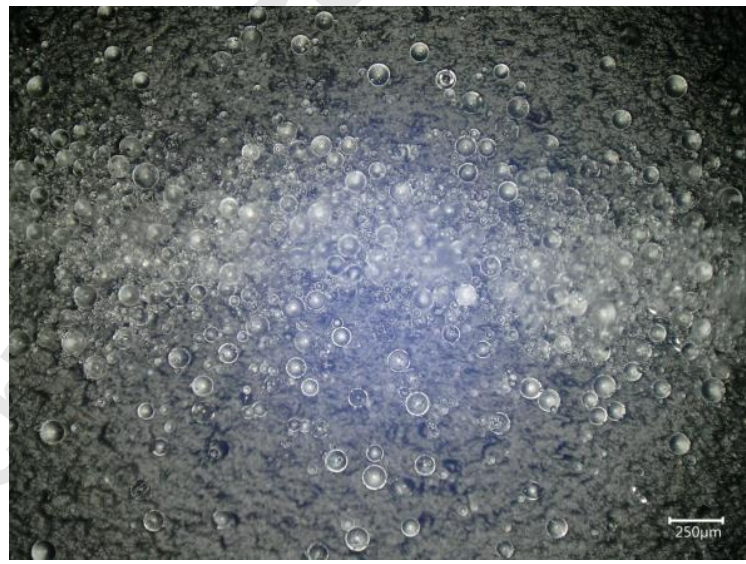

(d) Region C 
Fig. 12. Line width and cross section of the deposited soda-lime glass powders

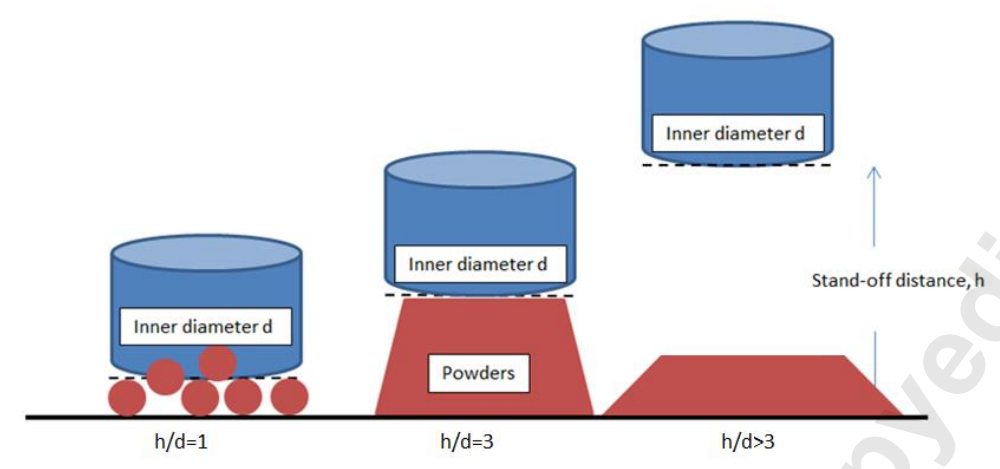

Fig. 13. Schematic of line forming mechanism in each region

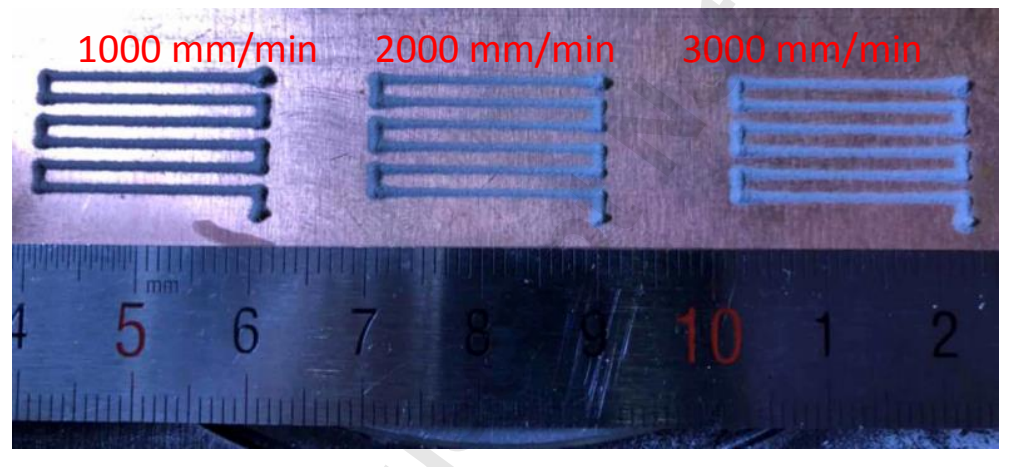

(a) 316L powders

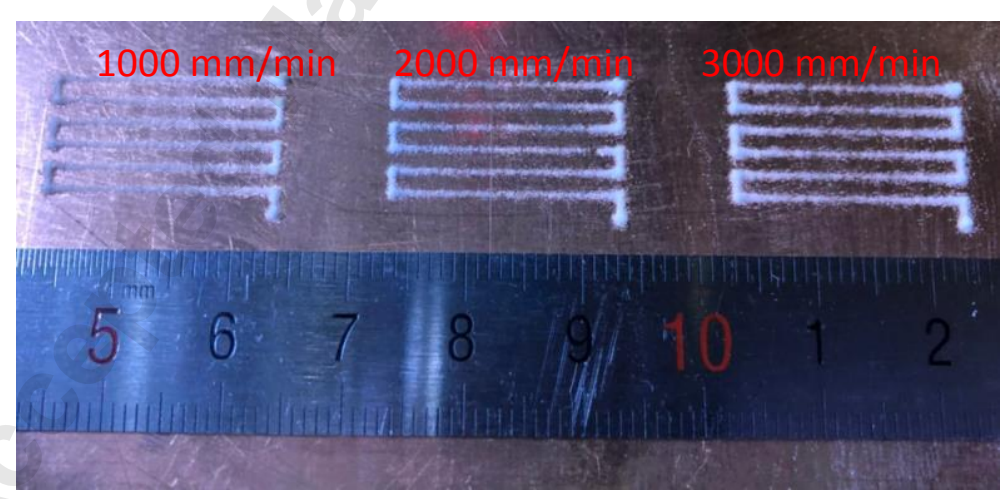

(b) Soda-limes powders

Fig. 14. Deposited lines at different speeds 


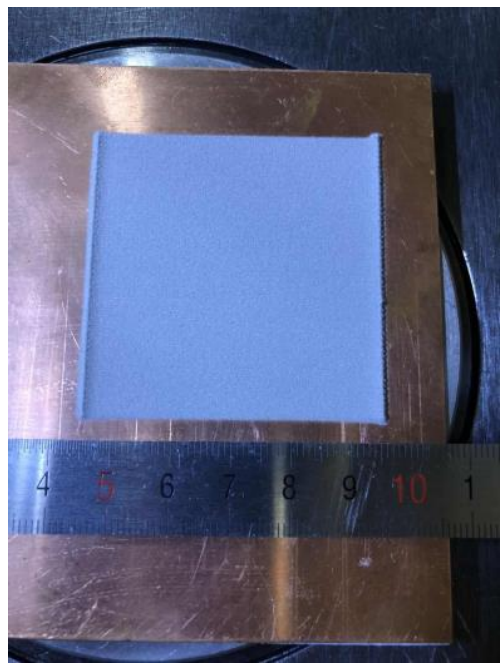

(a) The layer of 316L powders

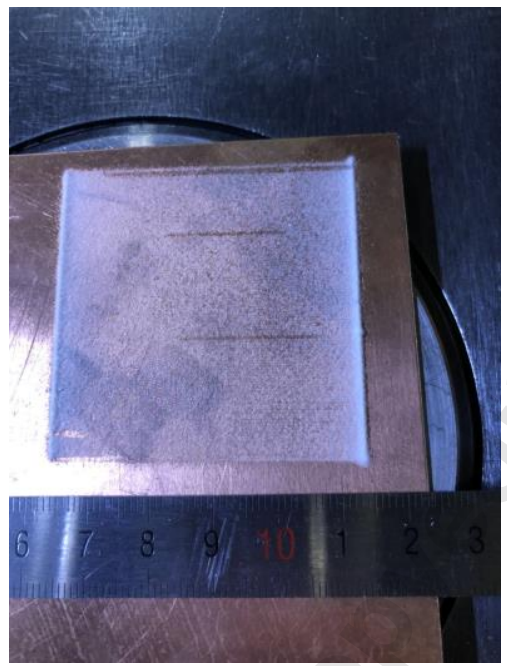

(b) The layer of Soda-lime powders

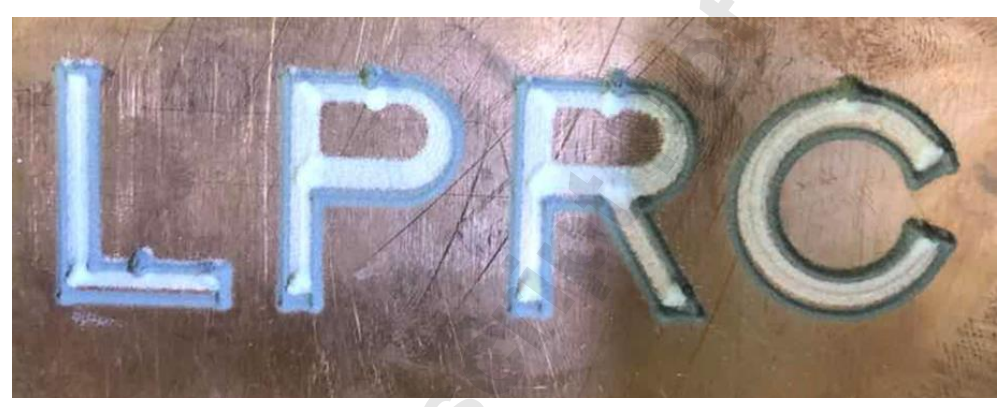

(c) The pattern of both materials

Fig. 15. Layers deposited by the system, (a) and (b) are the square layers; (c) is the pattern 'LPRC' from two different materials: 316L (outside) and soda lime glass (inside).
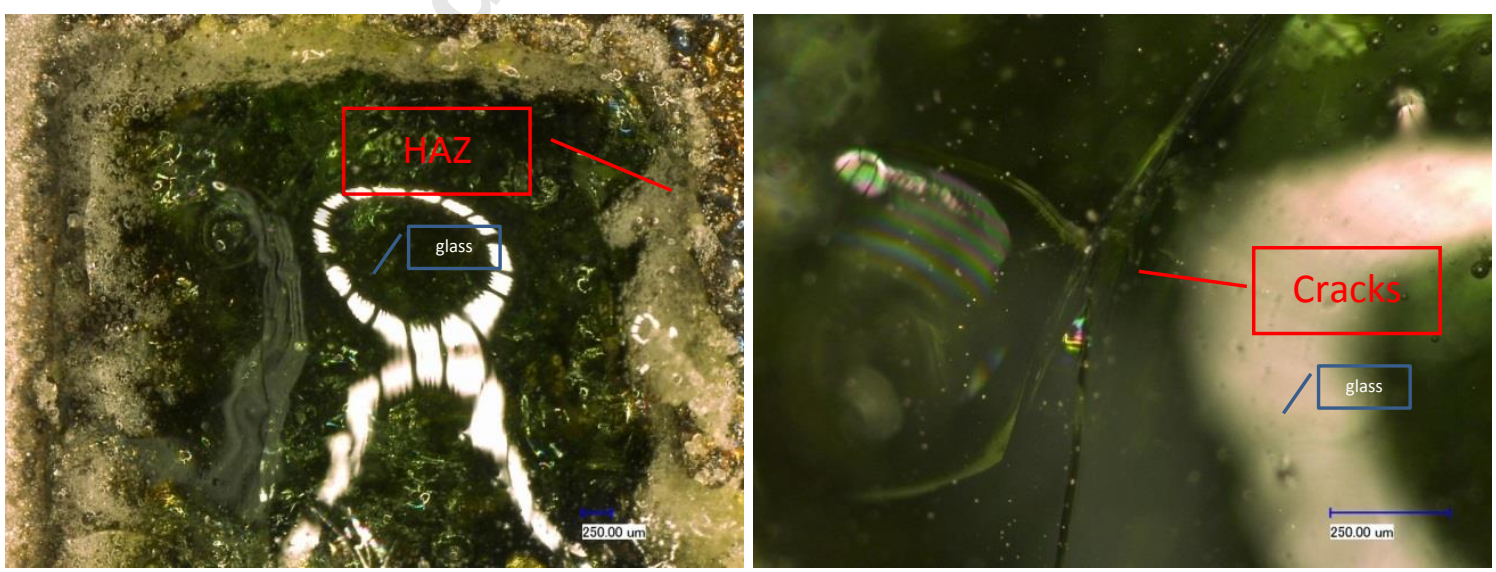

(a) surface
(b) cracks

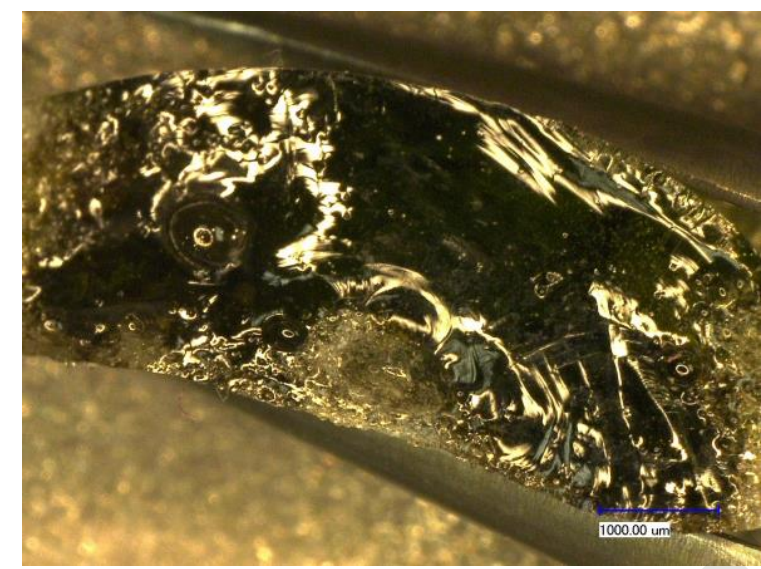

(c) The cross section of the block.

Fig. 16. The laser melted soda-lime glass block

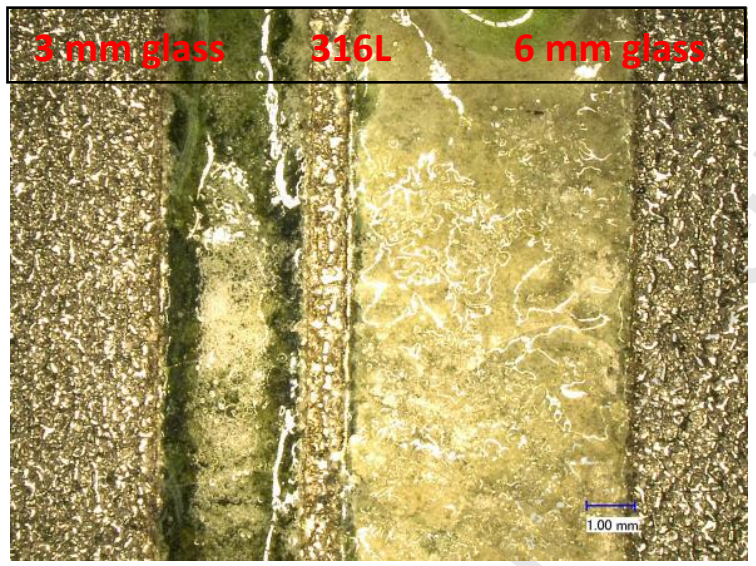

(a) The top view

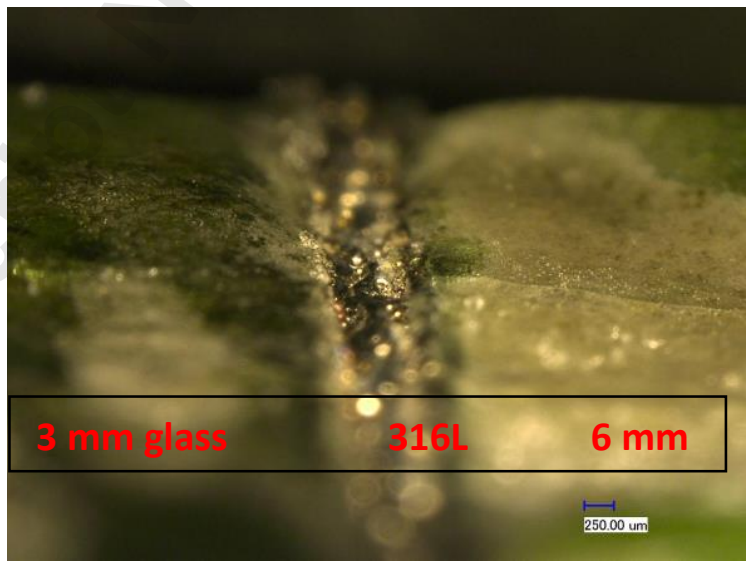

(b) The 600 inclined view

Fig. 17. Comparison between the melted $3 \mathrm{~mm}$ glass and $6 \mathrm{~mm}$ glass 


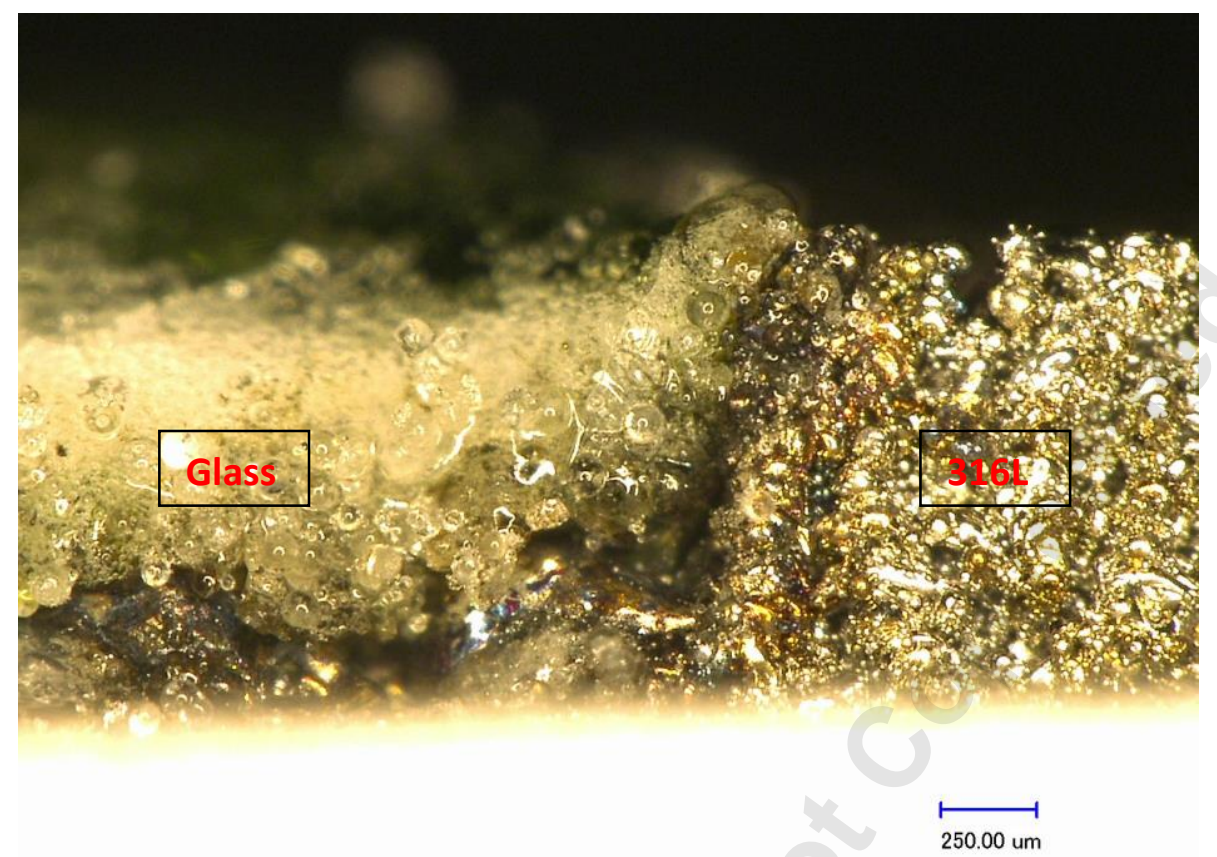

Fig. 18. The interface between metal and glass of the $3 \mathrm{~mm}$ width part from the cross section view

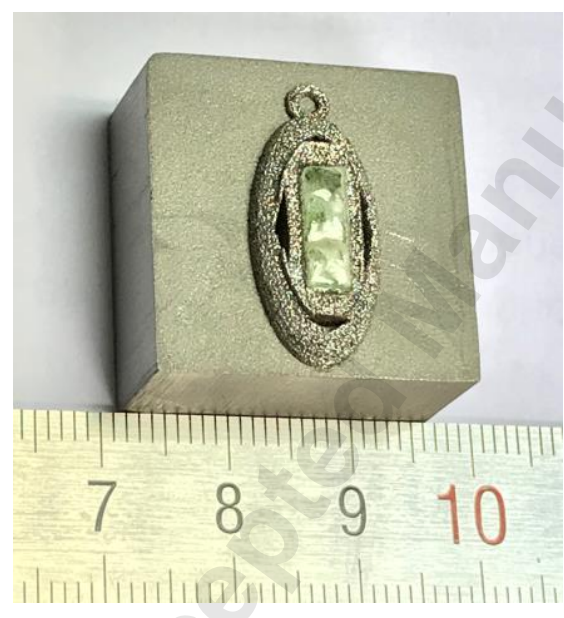

(a) The 316L-glass pendant

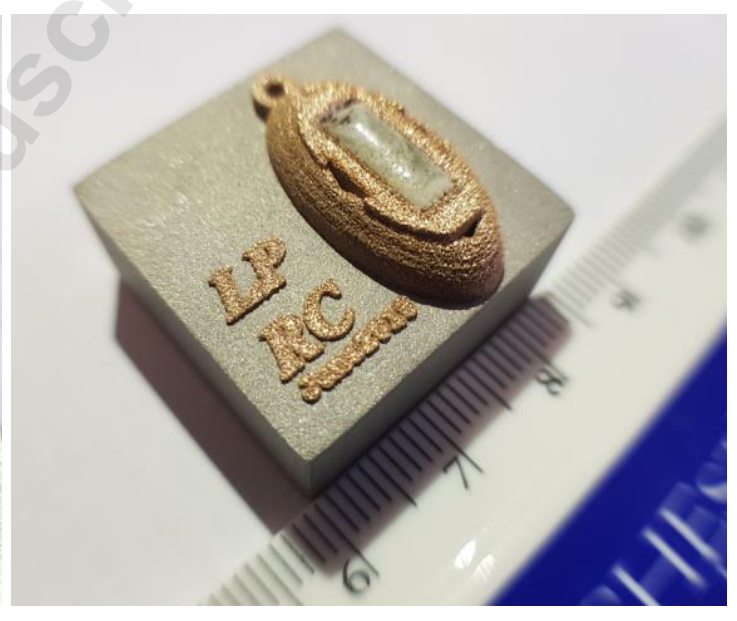

(b) The Cu10Sn-glass pendant

Fig. 19. The demonstration of metal-glass part made by the method 


\section{Table Caption List}

Table 1 Optimized laser parameters in this research

Table 2 Parameters of the flowrate tests

Table $3 \quad$ Flowrates of both $316 \mathrm{~L}$ and soda-lime glass by different orifice diameters and power using the dual PZT feeding system

Table 4 The parameters and results of different scanning speeds

Table 5 Optimized dispensing parameters used for making the pattern

Table 1 Optimized laser parameters in this research

\begin{tabular}{ccccc}
\hline Material & Power & Scanning speed & Hatch space & Scanning \\
& $(\mathbf{W})$ & $(\mathbf{m m} / \mathbf{s})$ & $(\mathbf{m m})$ & strategy \\
\hline 316L & 170 & 800 & 0.035 & zig-zag \\
Soda-lime glass & 180 & 300 & 0.05 & zig-zag \\
Cu10Sn & 125 & 150 & 0.1 & zig-zag \\
\hline
\end{tabular}

Table 2 Parameters of the flowrate tests

\begin{tabular}{|c|c|c|c|c|c|c|}
\hline \multirow[t]{2}{*}{ Specification } & \multicolumn{2}{|c|}{ Powder properties } & \multicolumn{2}{|c|}{ Vibrational parameters } & \multicolumn{2}{|c|}{ Orifice geometry } \\
\hline & Powder size & Shape & Vibrational & Vibrational & Orifice & Angle of \\
\hline
\end{tabular}




\begin{tabular}{ccccccc}
\hline & (microns) & & frequency (kHz) & power (W) & $\begin{array}{c}\text { diameter } \\
\text { (mm) }\end{array}$ & orifice \\
& & & & & & \\
\hline 316L & $10-45$ & Spherical & 28 & $6-60$ & $0.2,0.3$ & 30 \\
Stainless & & & & & & \\
Steel & & & & & & \\
Soda-lime & 30 and 90 & Spherical & 28 & $6-60$ & $0.3,0.35$ & 30 \\
glass & & & & & & \\
\hline
\end{tabular}

Table 3 Flowrates of both $316 \mathrm{~L}$ and soda-lime glass by different orifice diameters and power using the dual PZT feeding system

\begin{tabular}{ccccc}
\hline Power & \multicolumn{2}{c}{ 316L } & \multicolumn{2}{c}{ Soda-lime glass } \\
\cline { 2 - 5 } & $0.2 \mathrm{~mm}$ & $0.3 \mathrm{~mm}$ & $0.3 \mathrm{~mm}$ & $0.35 \mathrm{~mm}$ \\
\hline $\mathbf{6 ~ W}$ & $1.25 \pm 0.1 \mathrm{mg} / \mathrm{s}$ & $3.38 \pm 0.08 \mathrm{mg} / \mathrm{s}$ & $1.1 \pm 0.1 \mathrm{mg} / \mathrm{s}$ & $3.38 \pm 0.12 \mathrm{mg} / \mathrm{s}$ \\
& & & & \\
$\mathbf{2 4} \mathbf{~ W}$ & $2.07 \pm 0.08 \mathrm{mg} / \mathrm{s}$ & $12.02 \pm 0.13 \mathrm{mg} / \mathrm{s}$ & $1.27 \pm 0.02 \mathrm{mg} / \mathrm{s}$ & $4.18 \pm 0.05 \mathrm{mg} / \mathrm{s}$ \\
& & & & \\
$\mathbf{4 2 ~ W}$ & $3.02 \pm 0.07 \mathrm{mg} / \mathrm{s}$ & $28.4 \pm 0.1 \mathrm{mg} / \mathrm{s}$ & $2.13 \pm 0.05 \mathrm{mg} / \mathrm{s}$ & $5.37 \pm 0.08 \mathrm{mg} / \mathrm{s}$ \\
& & & & \\
$\mathbf{6 0 ~ W}$ & $4.45 \pm 0.05 \mathrm{mg} / \mathrm{s}$ & $31.53 \pm 0.09 \mathrm{mg} / \mathrm{s}$ & $3.12 \pm 0.08 \mathrm{mg} / \mathrm{s}$ & $5.80 \pm 0.05 \mathrm{mg} / \mathrm{s}$ \\
\end{tabular}

Table 4 The parameters and results of different scanning speeds

\begin{tabular}{ccccccc}
\hline Materials & $\begin{array}{c}\text { Stand-off } \\
\text { distance } \\
(\mathrm{mm})\end{array}$ & $\begin{array}{c}\text { Vibrational } \\
\text { frequency }(\mathrm{kHz})\end{array}$ & $\begin{array}{c}\text { Vibrational } \\
\text { power }(\mathrm{W})\end{array}$ & $\begin{array}{c}\text { Orifice } \\
\text { diameter } \\
(\mathrm{mm})\end{array}$ & $\begin{array}{c}\text { Scanning } \\
\text { speeds } \\
(\mathrm{mm} / \mathrm{min})\end{array}$ & $\begin{array}{c}\text { Line widths } \\
(\mu \mathrm{m})\end{array}$ \\
\hline
\end{tabular}




\begin{tabular}{|c|c|c|c|c|c|c|}
\hline & & & & & 1000 & $835 \pm 15$ \\
\hline \multirow[t]{3}{*}{$316 \mathrm{~L}$} & 1 & 28 & 24 & 0.3 & 2000 & $642.5 \pm 15$ \\
\hline & & & & & 3000 & $555 \pm 9$ \\
\hline & & & & & 1000 & $618 \pm 8$ \\
\hline \multirow[t]{2}{*}{$\begin{array}{l}\text { Soda- } \\
\text { lime }\end{array}$} & 1 & 28 & 24 & 0.35 & 2000 & $520 \pm 5$ \\
\hline & & & & & 3000 & $465 \pm 4$ \\
\hline
\end{tabular}

Table 5 Optimized dispensing parameters used for making the pattern

\begin{tabular}{cccccccc}
\hline & Orifice & Vibrational & Vibrational & Angle of & Scanning & Hatch & Stand-off \\
Materials & diameter & frequency & & speed & space & distance \\
& $(\mathrm{mm})$ & $(\mathrm{kHz})$ & power $(\mathrm{W})$ & orifice & & & \\
& & & & $(\mathrm{mm} / \mathrm{min})$ & $(\mathrm{mm})$ & $(\mathrm{mm})$
\end{tabular}

316L

0.3

Soda-

28

24

30

3000

0.5

1

lime

0.35 